\title{
Mulheres indígenas demarcam as eleições: Entrevista com Márcia Kambeba
}

\author{
Entrevistadora \\ Kena Azevedo Chaves \\ Doutoranda e Mestra em Geografia pela Universidade Estadual Paulista - UNESP/Rio Claro. \\ Pesquisadora do Centro de Estudos em Sustentabilidade da Fundação Getúlio Vargas - FGV. \\ Brasil \\ kenachaves@gmail.com
}

DOI: $10.5965 / 1984724622482021383$

http://dx.doi.org/10.5965/1984724622482021383 
Márcia Wayna Kambeba é mulher indígena do povo Kambeba, nascida na região do Alto Solimões e hoje radicada no estado do Pará. Márcia é escritora premiada, autora de livros e poesias publicadas no Brasil, Europa e Estados Unidos. Artista, ativista e professora, é mestre em Geografia pela Universidade Federal do Amazonas. Suas produções são atravessadas pela luta indígena e apoiadas na cosmologia de seu povo. Em seus trabalhos, Márcia recupera narrativas dos antepassados, traz à tona os seres encantados $^{1}$ e os saberes da floresta, provocando reflexões sobre as perspectivas epistêmicas dos povos e das mulheres indígenas.

Márcia Kambeba compõe atualmente o primeiro escalão da equipe de gestão da prefeitura municipal de Belém (PA), sendo a primeira mulher indígena e ocupar o cargo de Ouvidora Geral do município. Foi também candidata à vereadora pelo Partido Socialismo e Liberdade (PSOL), em Belém (PA), nas últimas eleições municipais de 2020 consideradas pelo movimento indígena como históricas pela quantidade de candidatos indígenas ${ }^{2}$, homens e mulheres, disputando cargos municipais. A participação das mulheres nos espaços políticos criados pelo movimento indígena tem crescido nos últimos anos, e sua presença maciça nessa eleição mostra a disposição e coragem dessas mulheres em enfrentar as estruturas de poder estabelecidas com bases coloniais no Brasil.

Nesta entrevista, Marcia Kambeba conta sua trajetória de vida, reflete sobre as lutas das mulheres indígenas e sua relação como feminismo, fala sobre as formas indígenas de fazer política e sobre as pontes possíveis com a política partidária; aborda temas como territorialidade, tempo circular e importância da narrativa para os povos indígenas, e as contradições da vida na cidade. A entrevista foi realizada virtualmente no dia 05 de setembro de 2020, e complementada com diálogos com a entrevistada realizados no dia 25 de setembro de 2020, no âmbito de sua participação na mesa de debate “Mulheres Indígenas e Atuação Política” (PET Geografia/Unesp Rio Claro).

\footnotetext{
1 Encantados são entidades que compõem a cosmologia de muitos povos amazônicos, são seres que habitam rios, igarapés e as florestas.

${ }^{2}$ Conforme dados da plataforma virtual campanhaindígena.org, as eleições de 2020 contaram com 2177 candidatos indígenas em todo o país.
} 


\section{Entrevista}

Entrevistadora: Márcia, conte um pouco sobre sua trajetória e seu envolvimento com as lutas do movimento indígena.

Márcia Kambeba: Sou Márcia Kambeba, sou do povo Omágua Kambeba, sou do Alto Solimões, no Amazonas. Nasci na verdade numa aldeia Tikuna, chamada Belém do Solimões. Nasci em 1979, ainda no período da ditadura, eu mesma não senti isso na pele, mas os meus parentes que me antecederam sentiram a dor de viver uma ditadura. Houve uma ditadura, muitos indígenas sofreram com o campo de concentração, sim. Nasci nesse período, nessa aldeia de um povo que não é meu povo de sangue, mas é de pertencimento de território. Eu me considero Tikuna de pertencimento de território. Nasci no território Tikuna e fiquei com eles até os 9 anos de idade, depois fui para São Paulo de Olivença/AM, que era o município mais próximo de Belém do Solimões, na época, pois Tabatinga não existia ainda como município. Me criei em São Paulo de Olivença, e ia para a aldeia para ter contato com o povo.

Cursei Geografia na Universidade do Estado do Amazonas (UEA), em Tabatinga. Terminei Geografia e fui para Manaus, fiz lá uma especialização em educação ambiental, sobre desenvolvimento sustentável na Amazônia. Logo em seguida, em 2008, ingressei no mestrado em Geografia, agora pela Universidade Federal do Amazonas (UFAM). Depois disso eu vim para o Pará, hoje vivo aqui em Castanhal no Pará, estou aqui há quase 10 anos.

Eu já vinha de uma luta indígena, eu digo que comecei essa luta vendo a minha avó, vendo como ela fazia seus enfrentamentos. Ainda na aldeia Tikuna comecei a entender o que é a luta indígena. Ali eu vi a minha avó sendo essa mulher guerreira. Entendi desde cedo que a mulher indígena ela é guerreira, e quer ser chamada assim.

Minha avó foi essa mulher guerreira e me mostrou como a gente pode fazer uma luta mostrando que também temos direito de voz, que a gente também tem respeito pelas nossas decisões e queremos respeito às nossas opiniões. Minha avó se chamava Assunta, ela foi a primeira professora a dar aula para os Tikuna, naquela época. 
Meu padrinho, que foi chefe da Funai de Tabatinga, ele deduz que minha avó vivia naquela aldeia desde 1973. Quando nasci, minha avó já estava lá. Ela viveu com os Tikuna aproximadamente 40 anos, vivendo com eles na Terra Indígena, casou-se por lá, e assim foi se construindo minha família e a minha luta.

Entrevistadora: Hoje, 05 de setembro, é o Dia Internacional das Mulheres Indígenas. Qual o significado dessa data para os povos?

Márcia Kambeba: Hoje foi o dia que Bertolina e Gregória foram estupradas e mortas; hoje, dia 05 de setembro, é o Dia Internacional da Mulher Indígena porque essas mulheres foram brutalmente violentadas, porque elas lideraram rebeliões em defesa de seu povo. Hoje, não é dia de se comemorar nada, é dia de reflexão, para pensar onde estão as Bertolinas e Gregórias nos dias de hoje; onde elas estão? Quais são os preconceitos sentidos, quais os direitos violados dessas mulheres indígenas? Qual a dor que elas sofrem ao verem seu filho morto na beira de uma estrada, porque madeireiro passou e atirou nesse jovem que estava saindo de uma reunião de liderança? Quem são essas mulheres? Como sangram essas mulheres? Elas sangram todos os dias, mas não é um sangue menstrual, é um sangue que jorra pela dor, pelo olhar sofrido que essas mulheres carregam. Isso é preciso pensar e refletir quando vamos falar dessas mulheres.

Entrevistadora: Podemos falar em um movimento de mulheres indígenas no Brasil?

Márcia Kambeba: Não posso te dizer que nasce no Brasil um movimento de mulheres indígenas porque a gente não pensa assim separadamente. Não são territórios criados por fronteiras, a gente não cria essas fronteiras territoriais de gênero. Mas temos a ideia de que a mulher indígena, como guerreira, ela quer lutar ao lado dos homens. Não posso dizer que não exista o feminismo indígena, há quem lute por um feminismo indígena. Existem mulheres indígenas que se dizem feministas, se entendem como indígenas feministas. Mas existem outras que dizem que não são feministas, mas que sim são guerreiras. A palavra guerreira tem outra interpretação, que não é o mesmo que feminismo. O feminismo na cidade não se aplica à vivência das mulheres na aldeia, elas 
têm outra perspectiva para entender a presença dos homens nessa luta, é uma luta coletiva. A gente luta em defesa da terra, mas não somos apenas os que protegem a terra, nós somos o próprio corpo da terra, entendemos a terra como nosso corpo, nossa alma, percebemos assim o território. O tempo para nós também não é o mesmo da cidade: na cidade o tempo é linear, na aldeia trabalhamos com o tempo circular, um outro tempo. Dentro desse tempo temos outra leitura de tudo o que acontece, temos outra cosmologia para entender a própria natureza. A natureza se manifesta de outra forma para nós, na espiritualidade, nessa conexão com um outro território, que é o território da ancestralidade. Isso é importante na cultura indígena.

Eu sou professora convidada pela UEPA, e quando entro nos territórios de outros povos e encontro essas guerreiras, essas mulheres, percebo o quanto elas têm uma força que se compara ao movimento das ondas, das marés, dos rios, há uma fluidez, uma imponência nessas mulheres. E ao mesmo tempo elas não estão ali para disputar território com os homens, elas estão ali para lutar junto, lutar pelo território, lutar por esse território que não é só físico, mas é memorial, cultural, sentido e percebido.

A luta das mulheres indígenas se dá dessa forma. Eu acho muito bonito quando estamos numa reunião e os homens estão ali cozinhando para a gente, fazendo café, almoço, fazendo o jantar, servindo a gente. Nem precisamos buscar a comida, ela vem até nós porque eles nos servem. Não há uma disputa, os homens não se negam a apoiar as mulheres, eles ficam ali conosco, curiosos em saber o que é que as mulheres estão falando. Eles ficam ali para nos ajudar, estão ali para fazer a melhor comida, o melhor café, porque eles estão servindo as guerreiras. E da mesma maneira quando tem a reunião dos homens, não estamos ali apenas para saber o que estão falando, estamos ali para levar o café, para levar o beijú, para servir também. Não existe essa disputa, existe sim uma luta por igualdade de forças, de representatividade. Nós somos lideranças, assim como os homens são liderança; somos cacicas, assim como os homens são caciques; somos pajés, como os homens são pajés. Procuramos manter o respeito entre guerreiras e guerreiros. 
Entrevistadora: E sempre foi assim, ou você percebe uma transformação no papel das mulheres, tanto internamente ao povo, quanto na interação com o Estado e com os brancos?

Márcia Kambeba: Nem sempre foi assim, mas a questão toda é cultural. Quando alguém vai pensar com olhar da academia é preciso ter muito cuidado. É preciso cuidar, olhar para que chão estamos entrando, para o território que estamos pisando. Mesmo eu sendo indígena, quando estou no papel de pesquisadora preciso entender o que exatamente estou buscando e qual é a cultura que estou adentrando, preciso entender como se processa essa cultura. Cada povo tem um modo de territorializar seu espaço, tem um modo cultural próprio, e esse modo é diferente do meu. O modo de pensar da mulher Kambeba não é o mesmo da mulher Juruna, não é o mesmo da mulher Kumaruara. Veja, é um complexo cultural muito grande e não podemos generalizar. Eu tenho que pensar que o tempo da minha avó, Assunta, não é o tempo da Márcia Kambeba; ela viveu outro enfrentamento que eu não vivo agora. Eliane Potiguara, lá atrás, viveu outro enfrentamento, sofrendo com a ditadura, não é o mesmo que eu vivo aqui. Eliane sofreu muito para que o sofrimento aliviasse para nós, hoje. Meus avós viveram tempos duros lá atrás para amenizar a situação aqui para gente. Minha avó viveu num tempo em que a cultura era ainda muito patrilinear, junto com os Tikuna, mas existem culturas matrilineares. A cultura do povo Kambeba é matrilinear, a mulher toma as decisões. Quando uma mulher Kambeba se casa com um homem de outro povo, Juruna, Apurinã, Xikrin, por exemplo, ele sai do território dele e vai viver na aldeia dela, ele assume a identidade dela. Ele não deixa de ser quem ele é, não esquece seu povo, mas naquele momento de luta, de enfrentamento, ele é Kambeba.

Os brancos não entendem muito nosso pensamento, nossa forma de viver e de nos relacionarmos. O machismo na cidade é muito mais visível que na aldeia. Na aldeia eles querem proteger, há uma proteção, uma necessidade de proteger e lutar junto com as guerreiras. Quando as mulheres vão para a cidade estudar, eles vão junto, vão para proteger, não querem que elas passem sofrimento na cidade. A relação de poder dentro da aldeia indígena não é a mesma relação de poder que existe na cidade, ela está 
presente, mas de uma forma diferente. Existe uma hierarquia, que é importante entender para poder compreender as territorialidades dos povos, dos homens e das mulheres.

Entrevistadora: Você hoje é pré-candidata à vereadora em Belém, e muitas outras mulheres indígenas estão lançando candidaturas para essa próxima eleição. Como você enxerga esse movimento e o que te motiva a ser candidata?

Márcia Kambeba: A gente precisou fazer ocupações. Nós lutamos por direitos coletivos, pelo direito ao bem viver, e esse bem viver pode ser trabalhado não só na aldeia, mas também queremos trazer esse bem viver indígena para contribuir com o coletivo da cidade. Queremos pensar o bem viver na educação, na saúde, na cultura, na educação ambiental. Como Belém pode se tornar uma grande aldeia Mairi - Belém era conhecida como Mairi, que é um nome indígena que significa centro -, como Belém pode ser tornar essa Mairi do bem viver? O equilíbrio ambiental depende muito do ser humano, e nós só percebemos isso quando começamos a pensar coletivamente.

Eu nunca fui da política partidária, meu partido político sempre foi a literatura, eu sou artista, sou ativista, sou poeta, compositora, escritora, palestrante, atriz, enfim, faço um pouco de tudo, ressignificando a arte que vem do branco e transformando para ser uma ferramenta da nossa luta. De repente, eu recebi o convite do Partido Socialismo e Liberdade (PSOL) para entrar na campanha, meu nome havia sido indicado para ser précandidata à Câmara de Vereadores de Belém. Num primeiro momento eu neguei, não me via dentro desse cenário; a gente sabe que é muito delicado adentrar nesses espaços de disputa de poder. Ali é uma disputa, o maracá precisa ser bem balançado para que o eco chegue longe, e existe um risco do nosso maracá ser quebrado ali dentro. Então eu sei onde estou pisando, sei que não é fácil estar ali, é conflituoso para mim, porque a política indígena é pensada de um jeito muito diferente da política partidária. Eu penso de uma forma diferente pois a gente pensa sempre no coletivo, o que é bom para mim tem que ser bom para o outro, e o que é bom para o outro tem que ser bom para mim. Não sou eu sozinha, temos sempre que pensar no coletivo. 
Nós, mulheres indígenas, percebemos que é necessário ocupar esses espaços, por mais que a gente não venha a ganhar a eleição, mas estamos fazendo esse barulho, dizendo "olha, estamos aqui", temos nossos direitos, queremos desengavetar os direitos que estão ali e fazer com que eles virem realidade. Temos alguns direitos ali que existem apenas na lei, não existem na prática. E se não tem lei que venha a contribuir com os povos indígenas, então a gente quer fazer, a gente sabe como fazer. E queremos ocupar esses espaços coletivamente. Eu aqui em Belém convoco os parentes indígenas, e aqueles que apoiam, para pensar de forma coletiva o bem viver, trazendo todos para construir junto com a cidade.

\section{Entrevistadora: Como a política é praticada pelos povos indígenas?}

Márcia Kambeba: Os povos indígenas já faziam política desde o momento em que o contato chega, e a gente faz política o tempo todo. Quando estamos lutando pelos nossos direitos, quando a gente se mobiliza, quando a gente fecha uma rua em Brasília e junta Kayapó, Kambeba, Tembé etc., e vamos juntos, vamos cantar, vamos dançar, mostrar que estamos exigindo direitos, isso é política. Quando a gente se reúne para fazer o Acampamento Terra Livre, isso é política indígena. Quando a gente se reúne no território, juntamos 200 mulheres e vamos discutir quais os direitos das mulheres, como podemos nos articular para melhorar: isso é luta política. O que é novo para a gente é a gente se filiar ao partido. A gente sabe como fazer política, nos ensinaram isso desde lá atrás, nossos antepassados, e agora estamos nos aliando aos partidos que querem nos dar as mãos para fortalecer nossa luta. Precisamos agora desses partidos para fazer essa luta dentro do Estado, por isso temos que nos unir a eles. O que queremos dos partidos é que eles compreendam que somos indígenas, temos um contexto, uma ideia, que às vezes não está encaixada nos moldes dos partidos. É preciso buscar entender essa nossa lógica, fazer esse diálogo para afunilar as ideias, para fazer a coisa acontecer.

Nós, povos indígenas, trabalhamos em coletividade, tudo o que é meu é teu, nada é meu, tudo é nosso, é a ideia do bem viver. E esse é um desafio: como fazer com que o bem viver seja compreendido pelo partido? Como o bem viver pode ser entendido e aplicado 
na gestão municipal, na construção das políticas de cultura, saúde, educação, questão ambiental, esporte, lazer, como isso pode ser construído? Aí entramos nós, povos indígenas, para trazer o bem viver, fazer o diálogo com a cidade. Estamos convidando para uma construção. Não queremos pegar o saber indígena e impor de cima pra baixo sobre ninguém, queremos trazer os indígenas para conversarem com a cidade, a cidade se abrir para ouvir o indígena e entender a sua pedagogia, compreender e respeitar o indígena no seu notório saber.

Entrevistadora: Como os povos indígenas estão se organizando para disputar essa eleição?

Márcia Kambeba: Este ano temos muitos pré-candidatos indígenas, entre homens e mulheres, é o ano eleitoral em que temos o maior número de indígenas que se colocam como pré-candidatos, seja com prefeitos, vereadores... Estão ali, querendo fazer a diferença. Temos o Daniel Munduruku, Pagu Rodrigues, Teresa Arapium, Coletivo de Mulheres Indígenas em Santarém, em São Paulo, aqui em Belém só estou eu, como mulher indígena. Não é fácil fazer campanha, mas eu não desisto, não saio, porque eu penso no coletivo, porque estou junto com outras mulheres fortes do Pará.

As pessoas que estão ocupando espaços dentro das câmaras municipais, já que estamos falando de uma eleição municipal, não nos representam. Apesar de sermos eleitores, de votarmos, darmos nossos votos, nesses mesmos municípios nossos direitos são violados: direito à educação, direito à saúde, direito à terra... A pandemia está aí, os números aumentando a cada dia mais, Manaus está no vermelho, Belém no amarelo, e os povos indígenas estão vivendo essa ameaça do vírus nos seus territórios.

É importante que os povos indígenas, os povos tradicionais, as periferias... todos precisam ter representatividade dentro das câmaras municipais. Queremos que as pessoas compreendam como respeitar a natureza. Queremos trazer as contribuições dos povos indígenas, trazendo a ideia do bem viver para contribuir com luta por direitos, pela efetivação dos direitos que temos e que não são respeitados. 
Precisamos convocar os indígenas e não indígenas para nos apoiarem nesse momento. Sem a força e a presença dos indígenas que vivem na cidade de Belém, sem o apoio dos indígenas que estão nas federações e associações, não adianta estarmos nessa luta, lutar sozinho ninguém vai. Todas as vezes que vencemos foi graças à união dos nossos povos. Todo dia no Brasil um indígena é morto. Nos matam de diversas formas, seja invadindo território, queimando florestas e animais, seja destruindo territórios sagrados dos povos, porque um pajé virou pastor, porque os povos deixaram de praticar suas formas tradicionais de resistência...

Eu penso que temos muita luta pela frente, a luta não pode ser particularizada em determinado território ou aldeia, a luta é ampla. Precisamos pensar as lutas em rede, pensá-las no Nordeste, no Norte, em todas as regiões onde a presença indígena ainda se faz. A luta precisa ser pensada com os parentes ainda não contatados, que estão sofrendo pressões e ataques, mesmo que a gente não os veja, a gente sente a dor desses parentes não contados. Essas lutas precisam ser fortalecidas. Há de se criar uma bancada para os povos indígenas também, precisamos somar com nossos parentes que já estão nos espaços do governo, como a Joênia Wapichana. Nós povos indígenas, precisamos nos unir. Esse é o momento, exige muito engajamento, muita união, de um saber do outro, de ter contato com o outro, chamar o outro para fortalecer no outro o espírito de continuidade.

Entrevistadora: Você acredita que essa estratégia de ocupar cargos no Estado é uma forma efetiva de descolonização?

Márcia Kambeba: Descolonizar e decolonizar tem diferenças. Descolonizar é difícil, mas decolonizar a gente pode. A decolonização, ela é possível, e ela acontece através da educação, através dos espaços de saberes, a partir do momento que a gente consegue trazer os professores, os alunos, para uma construção coletiva de um pensamento decolonial. Eu trabalho com a decolonialidade, seja através da literatura, da música, eu procuro decolonizar, chamar as pessoas para uma reflexão crítica e analítica de sua atuação no planeta. Quando eu faço um poema de cunho ambiental, estou chamando 
meu leitor para pensar sua pegada ecológica no planeta, pensar o que estão fazendo com suas vidas, se estão contribuindo com alguma coletividade. O que é o território para mim? O espaço que eu ocupo, a rua da minha casa, que território é esse na minha vida? Qual o mapa mental da sua rua, como ela estava quando saiu e quando voltou? E você fez o quê? Qual sua atuação? Com o que você contribuiu? Acredito que é através dessa reflexão que fazemos acontecer a decolonialidade.

A gente precisa fazer com que as coisas sejam ditas, da forma mais compreensível possível. Não adianta eu falar da forma como a universidade me ensinou e meu parente não compreender, e o branco também não compreender. É preciso decolonizar, a decolonialidade só acontece quando decolonizamos a nós mesmos, se eu não fizer esse exercício dentro de mim, eu não vou conseguir decolonizar jamais.

Se a política não acontecer dentro de mim, jamais vou fazer política lá fora. A política parte, primeiramente, do meu ser pessoa, do meu locus de vivência, que é minha casa: desse lugar eu penso meu bairro, minha cidade, meu país. A política é isso, e é fundamental, necessária em todos os aspectos. Decolonizar a política é fazer essa política a partir de nós, indígenas, ribeirinhos, povos tradicionais. Esse pode ser um caminho.

Entrevistadora: Vivemos num país que desvaloriza muito a literatura, como é ser escritora indígena no Brasil?

Márcia Kambeba: Estou escrevendo por uma editora estrangeira, que publica e distribui para o mundo inteiro. No meu livro, que eles vão publicar no ano que vem, eu falo dos encantados, da Matita, do Curupira, das lendas, que eu chamo de narrativas; eu ouvi sobre esses encantados na minha aldeia, então para mim não são uma lenda, eles existem de fato. Eu apresentei outros livros que trazem essas narrativas para várias editoras aqui no Brasil, e eu recebi de uma delas a resposta de que "a gente não publica ficção". Eu recebi isso, eles entendem que o que eu escrevo é ficção. Quando eu apresentei para essa editora eles quiseram publicar imediatamente. As minhas poesias estão publicadas em vários países da Europa. O Brasil precisa olhar mais para a literatura brasileira, precisa valorizar mais. Eu ganhei recentemente um prêmio internacional de literatura da Focus 
Brasil New York; eu sou a única a ganhar esse prêmio aqui pela Amazônia, a única indígena, mas ninguém “deu ibope” para isso. Não recebi nenhum convite da imprensa aqui no Pará. Eu sou uma indígena mulher amazônida, parece que isso não tem importância para o Brasil, parece que não vale nada. Mas esse prêmio não valeria nada se minha poesia não fosse lida, usada na escola com as crianças. Eu dei uma aula ontem para a pós-graduação em literatura, aqui na universidade, isso é muito legal, isso me faz ficar feliz e me sentir reconhecida. Eu lancei meu primeiro livro em 2013; em 2018, lancei o segundo; vou lançar agora em novembro mais um livro sobre educação indígena; ano que vem, lançarei um livro só sobre mulheres indígenas, e esse livro sobre os encantados, pelos Estados Unidos.

Minha poesia é política, ela fala das mulheres, da questão ambiental, fala da cultura, da identidade, de arqueologia, antropologia, geografia. Eu ensino os alunos o que é território e territorialidade lendo uma poesia minha que tem esse nome. A geografia está muito presente nas minhas poesias. A literatura, ela é isso; ela feita com meu olhar, meu ambiente, com meu sentimento de pertencimento. Mas eu preciso me impor para ser reconhecida. Essa mulher guerreira, ela precisa se impor, se manifestar de muitas formas; às vezes com o maracá, às vezes com meu abraço, às vezes com um pedaço de pau, eu preciso me impor.

Entrevistadora: Qual a importância da narrativa para os povos indígenas?

Márcia Kambeba: Narrativa é justamente essa transmissão pela oralidade, é o falar. A escrita é muito recente para nós, com o tempo nos ensinaram que era possível desenhar o pensamento. Para mim, a escrita é o desenho do pensamento. A gente começou a desenhar o pensamento em forma de letra, e precisamos ir para a escola do branco para aprender como desenhar essa letra. Esse desenhar o pensamento é justamente essa força que vem da palavra, essa força que vem da oralidade e que se transforma em letra e vira o que o branco vai chamar de literatura, e que eu chamo de desenho do pensamento. E essa narrativa é fundamental porque ela passa a memória dos mais velhos. Minhas narrativas vêm, em boa parte, das memórias dos mais velhos, mas hoje eu não tenho mais 
as minhas fontes, elas já se foram, meus avós e bisavós eram a minha principal fonte de narrativas. Elas se foram, mas me deixaram um rio de informações, que eu procuro não esgotar. Eu quero escrever enquanto vida eu tiver, por isso vou escrevendo aos poucos.

Esse prêmio me colocou na categoria de ficção, e aí eu fui entender, na cabeça deles lá o que eu escrevo é ficção, mas na minha não. Para nós isso é real, a Matita é real, o Curupira é real, eles aparecem para o Pajé no ritual. Mas eles nunca vão entender com esse meu olhar, porque meu tempo é outro, o tempo da narrativa indígena é o tempo circular, é um outro tempo. Que pode não ser o tempo da narrativa da cidade, que é uma narrativa linear, que obedece a uma outra temporalidade. A gente precisa compreender como essa narrativa chega, e como a gente vai transcrever essa narrativa para que ela não fique artificial no livro.

Eu escrevo de forma muito natural, estou aqui falando contigo e de repente parece que tem alguém me dizendo algo, o indígena é muito espiritualizado, eu não escrevo só, escrevo sempre acompanhada, tem sempre alguém soprando ao pé do meu ouvido.

\section{Entrevistadora: Como podemos compreender o tempo circular?}

Márcia Kambeba: Quando falamos de tempo linear na cidade pensamos em passado, presente e futuro, como uma linha reta, progressivo, sempre. Na cidade tem-se o pensamento voltado para o consumismo, para o capitalismo, todas essas coisas que se colocam como necessidade, coisas que temos que fazer a todo custo para o progresso, para o crescimento populacional. A evolução, na cabeça da cidade, deve acontecer sempre em detrimento dos ecossistemas naturais. Evoluir sem se preocupar com o passado, sempre imediatista. O tempo na cidade só olha para o presente e o futuro, o tempo está com pressa de chegar logo no futuro, passa pelo presente correndo para chegar no futuro.

O tempo do povo indígena é o tempo circular, é o tempo do maracá, o tempo da lua, é um círculo mesmo. É um tempo que não tem muita pressa de girar, ele está apoiado no passado, para entender o passado, no presente viver bem e preparar o futuro. O futuro ainda não chegou, mas é preciso viver o presente, preparar no presente o que outras 
gerações possam usufruir do que estamos vivendo agora. É cuidar do território, é manter árvore em pé, é manter o rio limpo e despoluído, para que as gerações que vierem depois da minha possam encontrar esse mesmo território do jeito que eu encontrei. Por que é que a gente fazia migrações? Por que migrávamos de um lugar para outro, nos desterritorializávamos e reterritorializávamos? Justamente para deixar aquela terra em pousio, para a natureza se recompor, e quando a gente fazia o caminho da volta, retornava para aquela aldeia, tudo estava renovado. Esse é o tempo circular, é o tempo sem pressa. O próprio ordenamento da aldeia, ele é circular para facilitar a comunicação, facilita que cada um olhe para o outro. O tempo circular é o tempo da solidariedade, o tempo do pensar juntos, de eu poder lhe ver e você me ver, o tempo de eu dar um grito e vir alguém me acudir. Hoje na cidade, vivemos trancafiados em grades, prédios, ninguém tem tempo de olhar para o vizinho. Na aldeia não, lá o ordenamento obedece ao tempo circular. O mundo da cidade é um mundo em construção, está sempre em transformação. O mundo da aldeia é um mundo construído, as bases estão estáveis, buscamos criar estratégias de resistência para manter essas bases.

Entrevistadora: Quais as contradições da vida na cidade para uma mulher indígena, crescida numa cultura que entende o tempo de maneira circular?

Márcia Kambeba: Viver na cidade não é fácil; primeiramente a gente passa por muitos preconceitos, e isso não só o povo indígena, temos que estar preparados para isso.

Mas ser uma mulher indígena na cidade é difícil, e é difícil porque ninguém está disposto a ouvir. Eu sempre digo que a gente não precisa de lugar de fala, a gente precisa de lugar de escuta. O lugar de fala já está em mim, é a pessoa que eu sou, a identidade que eu tenho já é um lugar de fala. Sou Márcia Kambeba, qual meu lugar de fala? O de uma mulher Kambeba. Eu sou educadora, qual meu lugar de fala? De uma educadora. Isso é o lugar de fala. Mas o espaço de escuta não. Esse é construído, precisamos buscar na luta, de forma estratégica, conquistar esse espaço. Seja na universidade, na escola pública, na Câmara de Vereadores, tem que buscar. E é preciso entender: que lugar de escuta eu 
quero construir, qual público eu quero atingir? Nem todo mundo vai aceitar a tua ideia. Muita gente vai dizer que é impossível, que é utópico demais.

A mulher indígena precisa lutar de muitas formas. Minha casa é um território. Por mais que ela seja de alvenaria, diferente da casa que eu tinha na aldeia, eu tenho que entender que essa casa é meu território sagrado: aqui tenho meu tabaco, meu cachimbo e eu fumo quando tenho necessidade; tenho meu rapé, tenho meu tawari, tenho meu fogão à lenha, que eu acendo para assar minha banana. O fogão à lenha, ele é necessário nas aldeias, ele tem um papel importante. Em qualquer casa temos fogão à lenha, mesmo que também tenha um fogão a gás. O fogão à lenha faz fumaça, e a fumaça espanta o espírito mau. Viver na cidade impõe para nós aprender a andar nos dois lugares, o mundo da cidade e o mundo da aldeia. São espaços diferentes, lugares e territórios diferentes. Construções muito diferentes, mas que podem trazer aprendizados. O que eu aprendo aqui na cidade precisa ser ressignificado quando eu vou para a aldeia, precisa colocar nesse aprendizado o olhar da aldeia. E a mesma coisa quando eu volto da aldeia para a cidade, preciso colocar meu pensamento um pouco na lógica da cidade.

A cidade não consegue se colocar como aprendiz de um povo que tem conhecimento milenar, um povo que tem notório saber, que é doutor por excelência. Os povos estão querendo ensinar a nossa forma, com simplicidade, mesmo sofrendo, mesmo vendo que os brancos estão nos matando, ainda assim a gente quer ensinar, a gente construir junto, ensinar a ser humano, a ser uma nação, e a gente sabe como fazer. Na aldeia não tem presídio, não tem hospício, não tem sanatório, não tem nada disso porque a gente tem uma psicologia que trabalha com a juventude e com as crianças desde que nascem, a gente sabe trabalhar os conflitos. Mas na cidade não, a cidade se atrapalha toda e por isso ela precisa encarcerar, precisa colocar à margem: asilo para velho, sanatório para doidos e presídio para ladrão, essa é a cidade.

Entrevistadora: Como compreender a territorialidade na perspectiva indígena?

Márcia Kambeba: Primeiramente, compreendemos o território como esse espaço de vivência, onde as territorialidades acontecem: canto, dança, grafismo, pintura corporal, 
narrativas; são todas territorialidades que permeiam e formam as nossas identidades. A identidade coletiva e pessoal. Eu discuto território e territorialidade numa disciplina que dou na Universidade Estadual do Pará - UEPA, na Geografia. Quando eu chego na aldeia, não tenho dificuldade, porque todos já compreendem isso tudo, já sabem o que é seu território e sua territorialidade. Eu às vezes posso levar um pouco de conceitos, dialogar com autores como Rogério Haesbaert, mas sem impor essa teoria como verdade. O que importa é a ideia do povo sobre a sua própria territorialidade. Para ensinar o que é território e territorialidade eu digo: isso é o território, o construído, essa aldeia é o território. A territorialidade é a forma como o rio é sentido e percebido por todos que vivem ali. Qual a importância do rio? O que o rio traz? Qual a pedagogia do rio, o que ele ensina? O que os pássaros transmitem de conhecimento e tradição? Isso é territorialidade. Como a pintura corporal representa e significa para todos nós, qual o signo de comunicação que ela nos dá de povo para povo? Isso é territorialidade. Tanto territorialidade, como território, são simples e naturais de entender para a gente, a gente convive e usa essas ideias perfeitamente dentro de um olhar indígena, mas também de um olhar que vem da cidade a partir da ciência.

Entrevistadora: Obrigada, Márcia!

Márcia Kambeba: Obrigada!

Recebido em: 24/10/2020 Aprovado em: 05/02/2021

Universidade do Estado de Santa Catarina - UDESC Centro de Ciências Humanas e da Educação - FAED

PerCursos

Volume 22 - Número 48 - Ano 2021 revistapercursos@gmail.com 